lowered vitality of the tissues. The toxic origin of the disease is supposed to receive support from what is known of the action of phosphorus on the liver. When this substance is swallowed in poisonous amounts it first gives rise to intense gastric irritation, which may subside, to be followed a few days later by fatal symptoms associated with the liver, chiefly jaundice and local pain and tenderness. After death in such cases the organ is found to be in a state of extreme fatty degeneration, which is sometimes spoken of as acute yellow atrophy, though the organ may, in point of fact, be greatly enlarged, as it was in a case of poisoning by phosphorus under the care of my colleague, Dr. Caton, in 1898, where the liver weighed 3 lbs. $14 \mathrm{oz}$.

The prognosis is extremely grave though, perhaps, not altogether hopeless, since recovery has been recorded in cases which presented all the characteristic symptoms of the disease, including diminution of the liver dulness. The possibility of considerable restoration of the lost liver substance is suggested by the observations of McPhedran and Macallum, of Toronto ${ }^{5}$ who found evidence of abundant cell division in a liver which weighed only $25 \mathrm{oz}$., and Ziegler states that where life is preserved a compensatory hypertrophy of the surviving portions of the liver substance takes place.

If the case be seen in the early stage before the symptoms characteristic of acute yellow atrophy have appeared the treatment commonly employed in cases of catarrhal jaundice will naturally be adopted. When the characteristic symptoms have been added unfortunately we know of no line of treatment which seems to have the slightest infuence on the progress of the disease. All we can do is to endeavour to maiutain the patient's strength in the hope that the morbid influences, whatever they may be, will exhaust themselves, promote the action of the kidneys so as to facilitate the elimination of toxic and other waste products and treat symptoms as they arise.

The chief practical lesson which we ought to derive from the consideration of the foregoing cases seems to me to be that although the majority of cases of simple jaundice are among the mildest of the diseases which come under our notice, we should never look on them as trivial; but remember that what has all the appearance of an affection which will disapprar in a few days may in reality be the beginning of a formidable disease which will carry off the patient in as short a time.

(1) speciellen path. Anatomie, gth Aufl. s. $586 . \quad 2$ Fagge, Prin. and Pract. of Med., and ed.vol. i, p. 10. Waters, Contributions to Clin. and Prac. Med., p. 179. 4 Chauffard, Traite de Medecine, Charcot and Bouchard, Tome iii, p. 766. 5 McPhedran and Macallum, BRITISH MEdicAL JOURNAL, 1894, p. 293

\section{ON THE TREATMENT OF WOUNDS IN WAR.}

Being a Portion of an Address Delivered before the Midland Medical Society.*

By W. WATSON CHEYNE, C.B., M.B., F.R.C.S., F.R.S., Professor of Surgery, King's College, London; lately Consulting Surgeon with the Field Force, South Africa.

[Professor Watson Cheyne commenced his address by observing that two important questions arose in reviewing the suryical experience gained in South Africa: (I) Should the experience gained with regard to the treatment of gunshot injuries in war lead to any modification of the rules which had been gradually formulated for the treatment of similar injuries in civil practice? (2) How far had the principle of modern surgery, and especially of asepsis, been acted on and how far was it necessary and possible to act on them? Aft $r$ considering the tirst question and answering it in the neyative, Mr. Cheyne turned to the second question and spoke as folluws:- ]

In considering this matter of the relation of the results to he treatment adopted we must divide the treatment into two stages-namely, that which takes place in the field and that which is carried out at the base hospitals, and my statement only applies in so far as regards the treatment of the patients in the firld be'ore they arrive at the base hospitals. When

* The full text is published in the Birmingham Medical Review for November, 190r. the cases reached the base hospitals the value of the recent advances in surgery at once came into play and the results from that period onward were of course incomparably better than they would have been before these recent developments had taken place. But in the first class of case, namely, those treated at the front, I believe that modern surgery and active asepsis had very little to do with the results, and in $\mathrm{mJ}$ opinion these results are mainly attributable to the character of modern bullet wounds, and to the climate in which these wounds were inflicted. In fact, I would go so far as to say that if these wounds had been made with the old round bullet and in a damper climate (say in the Crimea) the immediate results under the methods of treatment adopted in the field would not have been so very much better than those formerly obtained, in spite of the recent advances in surgery and the introduction of Listerism. Perhaps this is going a little too far because, although I cannot attribute the results obtained to any active application of the advances of modern surgery or of asepsis, still the treatment contributed considerably to the result in that, while in former days wounds were meddled with, probed, opened up, poulticed and so forth, in the present campaign they were left alone and mischievous interference was avoided. Probably the small size and apparently trivial character of the wound led to the plan of leaving it alone in the first instance, and this plan was further necessitated owing to the large number of wounds which occurred in the early battles, the consequent difficulty of finding time 10 open up these wounds, the small personnel and the other difflculties to which allusion will be made; and no doubt added to this there is unquestionably a diminishing tendency to interfere actively with wounds as the result of the experience of modern surgery. But this is a different matter from saying that the results obtained were due to modern surgery and asepsis, in so far as that implies an active application of those principles.

It is only necessary to consider the circumstances under which a man is wounded, and the various steps which have to be gone through before he reaches the base hospital in order to see how extremely difficult it is to apply modern surgical principles in the early treatment of these cases, and it is only by the study of these conditions that one can hope to lay down lines for progress in the future.

Let us look first at the conditions under which a man is wounded in the field. He is probably lying on the ground, perhaps behind a stone or an ant-heap, and all around him there is a shower of bullets which renders it quite impossible for anyone to walk up and attend to his wound properly or to carry him off the field and have him attended to at the dressing station. He must lie where he is till the action is over, or at any rate till it has passed away from his vicinity and the only assistance that he can get in the first instance will be either by his own efforts or from a comrade, or from the regimental doctor, who makes his way to him as best he can, and naturally as unencumbered with apparatus and paraphernalia as possible. Under these circumstances what happens to the wound? He goes into the fight provided with what is called a "field dressing," which essentially consists of a small piece of antiseptic gauze, a piece of wool, and a bandage. The gauze is quite small in amount, and, if there is any bleeding going on, it very soon becomes saturated with blood, and, to begin with, contains such a emall quantity of antiseptic material in it that the blood passing through it is not in any way deprived of the possibility of putrefying, so that this little dressing, as arranged in the packet which accompanies each soldier, is more s sort of clean rag than any actively antiseptic dressing. But under the circumstances in which it is employed it is very far from being even a clean rag. If the soldier or his comrade attends to the wound, they open this packet; their hands are covered with mud and sand and grease; they take out this piece of gauze with their dirty hands; very probably they lay it down on the ground while they are getting the clothes opened, and then they stick this piece of dirty gauze on the wound. And even if the dressing is made by the doctor the conditions are practically no better. He cannot carry bottles of lotion with him into the firing line; he cannot even wash his hands; and, though perhaps he may take a little more care that the piece of gauze does not get badly soiled, yet even in his hands with the greatest care this 
dressing is by no means an aseptic dressing, and to speak of it as an aseptic dressing, or to speak of such treatment of a wound as in any way an active application of Listerism, is, of course, an absurdity.

In a good many cases the man now lies on the ground for some considerable time, perhaps even for hours, exposed to the heat of the sun, and by the time that he reaches the dressing station or the field hospital the blood and dressing very often form a dry hard cake over the wound, which requires some little force to detach, and in many cases of small bullet wounds, if this cake of blood and gauze be left undisturbed for some days, it will be found when it comes off that healing has occurred under the scab. When the patient has arrived at the dressing station, even in cases where it is essential that the wound should be redressed, and where, therefore, the opportunity for thorough disinfection is presented, practically little or nothing is done in that way, mainly, of course, owing again to the circumstances of the case. At the same time, I may say that I did come across a few men who, in spite of the circumstances, made a fairly efficient attempt to carry out disinfection of the wounds as soon as they came under their care; but in the majority of cases the lotions at hand were quite insufficient and inefficient, and practically no real disinfection was carried out.

In the circumstances of the present war the chief obstacle to the thorough treatment of wounds at the front was connected with the water supply. In the first place the supply of water was deficient, and the ponds were a considerable distance apart, and it was by no means always possible during an engagement to arrange that the field hospital should be in such a position. that an ample supply of water was obtainable. In the second place, even if this difficulty were overcome, the water was invariably bad and so extremely muddy that even after precipitation with alum the filtration was extremely difficult. In fact, a great deal of time and labour was required in the attempts to filter the water, for such filters as were efficient, such as Chamberland's and Berkefeld's filters, very quickly became clogged with the mud, and had to be repeatedly taken out and cleaned. One can easily understand that with a staff that was undermanned and working under high pressure it was difficult to find anyone who could be told off to collect and filter water, besides which the filtering of this water, on account of its muddiness, was a very slow process, and thus only a small quantity could be obtained in a given time. The third difficulty was the impossibility of obtaining boiled water. In the early stage of the campaign the transport was so cut down that only the number of kettles necessary to prepare food for the patients was provided, and there were no extra kettles available for boiling water for operation purnoses, and further, the obtaining of fuel was a very great difficulty. The country itself is devoid of fuel ; the absence of trees renders one dependent on the stray pieces of wood that one can pick up, such as the posts of wire railings, enclosures round the houses, and so forth, and the staple fuel used in that country is cow dung, which was not always obtainable.

It is thus evident that during the progress of an engagement, if lotions and sterilised water had not been made ready beforehand, it was really quite impossible to obtain the proper lotions or even for the surgeon or the attendants to keep their hands decently clean. In many cases no lotions were available at all, or if they were they consisted of some muddy water into which a little carbolic acid or sublimate was introduced-lotions which, I believe, were quite incapable of destroying even the most delicately-constituted bacterium. Hence in cases where it was thought advisable to change the dressing there was no proper disinfection of the skin around the wound. Indeed, in the majority of instances, another piece of gauze, which was very often, owing to the amount of dust and sand in the air and the absence of water to enable the surgeon to wash his hands, nearly as dirty as the former was put on and this could very seldom be described as an aseptic dressing.

The difficulties of aseptic work were also much increased by the amount of sand and dust present in the air. The veld though in the springtime covered with grass, does not possess a closely-knit turf as in this country; the condition is more a series of tussocks of grass with sand between, and after the ground has been passed over by waggons or by soldiers these tussocks very soon become destroyed, and the whole ground is converted simply into a sandy desert. Hence the air was always full of sand, and with a little wind there were constantly dust storms, so that the dressings and other materials became saturated with this sand. And lastly, flies were extremely troublesome, especially where the camp was near water, and these were constantly trying to settle on wounds when they were exposed to view, and of course interfered with the aseptic arrangements.

I have said nothing as yet as regards another very great difficulty in carrying out the requirements of modern surgery, namely, the question of transport of the patients to the base hospital. The wounded when they were brought back to the dressing station or to the field hospital, were not put in comfortable beds and allowed to remain until their wounds were healed. In many cases, indeed, only a few hours elapsed, and they were then again put into an ambulance waggon, or an ox or buck waggon, and carted off either to the nearest base hospital or to the nearest point on the railway line, from whence they were transferred to the base. In some places, such as Paardeberg, these journeys of the recently wounded in ox waggons lasted for two or three days. One can easily imagine how deleterious such transport was, and what such a journey would mean to a patient with compound fracture of a limb, or with a fractured spine, or an abdominal injury or a fracture of the skull, and no one can be surprised to learn that deaths in these cases frequently occurred during, or as a result of, the journey. The conditions were not so bad where the engagement occurred in the immediate neighbourhood of a railway line, and where the wounded could be quickly transferred to a well-appointed hospital train, but even there they had to suffer in the transit over the rough veld.

That the results could not have been obtained if the wounds had not remained aseptic is, of course, self-evident; but the point is that this asepsis was not brought about by the surgeon, but depended on the climate and the nature of the bullet wound.

It must, not, however, be supposed that bullet wounds invariably escaped sepsis. On the contrary, a considerable number of cases even of the small wounds inflicted by a rapidlytravelling bullet had suppuration along the track. In these cases, although, so long as only soft parts were injured, this did not matter very much; nevertheless, when bones were broken, necrosis and other troubles were apt to follow. In cases, however, where the wound was an inch or larger in size, in my experience sepsis invariably occurred; and though many of these wounds healed ultimately well enough when they reached the base hospital early, I have seen some extremely rapid cases of acute septicæmia and emphysematous gangrene, and in many cases severe and prolonged suppuration with osteo.myelitis, and some were only rescued by early and high amputation.

The explanation of the escape of a large number of the cases of small bullet wounds depends, as has been already said, partly on the nature of the wound inflicted by the bullet, and partly on the climatic conditions under which the injury took place. Wounds made with these small conical bullets vary a good deal in their chararter. On the one hand, if the bullet is travelling rapidly and strikes straight, and either passes through the soft parts or through the cancellous ends of bones, it generally makes only a small punctured wound of entrance and a slit or small wound of exit. On the other hand, when the bullet is spent it may strike sideways or obliquely, just as it may also do in a case of ricochet. If the rifling of the gun is worn it may also strike obliquely, or, if it strikes the shafts of bones and breaks them up, it may produce almost an explosive wound. In all these cases a larger wound is produced. The great majority of wounds, however, are, as has been said, very small, and differ very markedly from the old wounds with round bullets. In the first place these bullets seldom take in any portion of the clothing so that the wound does not become soiled from this cause, and apparently also the bullet seldom takes in any septic material. The most frequent cases where that occurs are where the bullet passes through stockings, flannel shirts, etc. Again, the aperture of exit is not larger than that of entrance, as used to be the case, and the injury to the tissues in the shape of bruising is usually comparatively slight. In fact, in many 
cases the tissues are not so much bruised as pushed aside by the missile. The consequence is that the wound is, as a rule, quite small; there is no cavity in the interior because the muscles are separated rather than divided, the sides of the wound come together at once, and these sides are fairly healthy; hence, unless in cases where the bullet has carried in septic material, or where the skin and the part injured are very septic, the majority of the wounds heal without any trouble.

But as important as the size and nature of the wound are the conditions under which it is inflicted. I need not recall to your minds that a certain and large amount of moisture is necessary for the growth of bacteria, and that the concentration of organic fluids is one way of preserving them. Nor need I point out that healing by scabbing, which is an old and long-recognised method of healing, acts on this principle, the blood drying up and becoming concentrated before the bacteria have had time to grow in it. This principle has been recognised for many years, and various attempts have been made to promote the rapid scabbing of wouncis by powdering them, by blowing air on them and so forth.

Now, in South Africa the climate is especially advantageous in that it promotes rapid drying up of the blood effused and healing under a scab. The excessive dryness of the air and the heat of the sun contribute to this result in a way that can rarely be found elsewhere and this was more especially the case seeing that the bleeding from these wounds was generally quite slight, so that only a small quantity of blood had to dry up. The antiseptic dressing and the surgical treatment adopted had little or nothing to do with the result in these cases and the only way in which we can bring in modern surgery as of value is because it has taught us the meaning and value of healing under a scab and has shown us that unless the wound can be made thoroughly aseptic the less such a scab is disturbed in the first instance the better. That the essential elements in these wounds are the bullet and the climate is shown by the following facts:-In the early stages of the war the field dressing which was provided contained a piece of mackintosh which the soldiers were instructed to apply outside the gauze. When this was done, however, it was found that sepsis and suppuration frequently occurred along the' track of the wound and I have seen a number of cases brought in only a few hours after the infliction of the injury dressed in this way, and have found the gauze and discharge stinking, and of course, entire absence of scabbing. This was observed quite early in the campaign, and from that time orders were issued that the mackintosh was not to be used. But this very fact shows that the drying up of the discharge and not the antiseptic dressing was the important factor. It was also observed that those cases did best where the wounded lay out in the sun for a long time before they could be brought in, and where, therefore, a rapid and very dry crust formed. The size of the wound has naturally also a good di al to do with the result. Where the wound was too large or the effusion of the blood too great to permit of the formation of a rapid crust, sepsis was almost certain to occur, and, as I have just said, I have seen some very severe septic cases under these circumstances; indeed, I have never seen a wound of any large size which was not septic. And we must remember that the great majority of deaths which occur a few days after an action result from sepsis of the wounds, so that the results as regards asepsis where we consider cases of large wounds without crust formation are by no means so favourable as one would at first think when all the cases are grouped together.

It is thus evident from all that has been said that we were dependent for the success which followed in this war in so far as the treatment at the front is concerned, not on advances in surgical science, but on the merciful nature of the modern bullet wound and on the climate in which the fighting took place; and as I said before, if a larger bullet were used and if the fighting took place in a moist climate we could hardly expect anything like similar results. The question therefore arises, On what lines should the treatment of wounds be carried out in future?

It is quite clear that in no case can we hope for real asepsis from the first. The chances of getting the wounded out of the firing line quickly are becoming less and less; indeed the wounded themselves are very much safer if they are left alone, provided they have any protection at all, for they rum a great risk of being killed or wounded again if an attempt is made to carry them out. Further, the surgeon in the field cannot carry about lotions or water to wash his hands, and the first field dressing must in a large number of cases be applied by the patient or his comrades. So that till the patient reaches the dressing station at any rate, and very probably the field hospital, there is no possibility of carrying anything like active aseptic treatment into force, and some considerable number of hours may have elapsed before the patient comes under these conditions. It seems to me, therefore, that it is only in the way of aiding the principle of rapid drying up of the blood and obtaining a good scab that we can help matters in the first instance, and the only way in which I see that we can do this is to resort to the attempts to promotescabbing and prevent decomposition by the free use of antiseptic powders, and by the free exposure of the wound to air and sun. The object of these powders would be partly to absorb moisture, and therefore tend to make a cake, and partly also, being antiseptic, to impregnate the blood with such a quantity of antiseptic material that bacteria cannot grow in it. The first point is the more important. As to what powder should be used, that is a matter that would need to be worked out, but I think that powder would be better than pastes, especially if these contained gummy materials, because the drying up of the blood would occur more quickly, and of course the use of anything in the shape of ointments would be to give up the whole principle of scabbing, and would not, I am sure, meet the requirements of the case. I think if, in addition to the cyanide gauze, there was in the field dressing a packet of antiseptic powder, which the soldier was instructed to open and sprinkle over the wound before applying the gauze, or if the gauze itself were full of loose powder, considerable help would be obtained. Further, the regimental surgeon, although he could not carry antiseptic lotions with him, might quite well carry a quantity of antiseptic powder and dust the wounds with it before applying the dressings. I tried this when I first went out, and furnished various bearer companies with pepper boxes containing various antiseptic powders of different strengths and kinds, but, owing to the ever-changing position of the bearer companies, I never knew what the result was, or indeed if they had ever been used. This is a point which, $I$ think, might well be looked into by the authorities.

The question of a proper supply of water and lotions must be also thoroughly gone into. In such a country as the Free State it is clearly essential to provide the lotions and waterbefore the engagement. In the case of an engagement one cannot always find a supply of water near which the dressing station or field hospital can be pitched and, even if it is found, it is sure to be muddy and require filtering and boiling,conditions which, as I have already mentioned, are quite unattainable. It is true that water-carts accompany the hospitals, but one of the most distressing symptoms of the wounded is thirst, and the water in the water-carts must be reserved for drinking purposes, and is often indeed quite insufficient for that. It seems, therefore, that it is essent: a that arrangements should be made by which the field ambulances and bearer companies can carry into acticn $\mathrm{a}$. quantity of water which has been filtered and boiled and lotions which are ready for use, and I do not see that there can really be any serious difficulty in doing this. After we left. Bloemfontein I was provided with an ambulance cart of wy own in which I carried an operating tent and all the requisites for performing operations, and I made a point of having at hand a number of rum jars which were kept filled with strong lotions, which could be diluted as required. I also had a jar full of swabs soaking in lotion and a large tiglit. gallon tin which I always kept replenished at every opportunity with filtered and boiled water. It really took very little time to keep the se vessels replenished, and one was. always ready far any reasonable emergency. If I could do this with the limited assistance and transport at my disposal I see no reason why it should not also be done in the beart companies and field hospitals. Although in many of the ordinary small wounds it is best not to disturb the crust, if $u$ good crust has formed, still in larger wounds the nnly chance of avoiding sepsis is by thorouy th disinfection of the skin and wound as soan as possible. 
One other point to which I would call attention as interfering with the application of modern surgery is the difficulty in illumination in the operating and other tents. As a rule it is night before the wounded can be brought in and attended to: at any rate in most of the cases which I saw the dressing and operating work had to be done after dark. In our field hospitals the arrangements for illumination were very imperfect and usually consisted of candles, which either had to be held by an orderly, or, owing to the small staff, had to be stuck in a dirty lantern or on a bit of wood. The only two abdominal sections which I did were both done late in the evening with the aid of a candle stuck in a piece of wood, and placed as near the wound as possible. In several of the foreign ambulances the acetylene light was provided, and in the cart which I organised at Bloemfontein I was fortunately able to procure and carry with me a small acetylene generator, which gave the most brilliant illumination. I would call attention to this point because I do not see that there can be any great difficulty in providing illumination of this kind to the various field hospitals, and it is a matter of the very greatest importance. For a field hospital to go into action without lotions, without water, without means of boiling water, or without proper illumination, is just as bad as for guns to go into action without proper fuses for the shells, or for the men to use black powder. These things are absolutely necessary equipments for the work, and if additional transport is required for them it must be provided.

One other question arises with regard to the better treatment of the wounded, and that is the question of the necessity of transporting them to the base. The ideal treatment would be to arrange for the field hospital to be left on the field of battle, and for the patients to be retained there till it was safe for them to be transported to the base. Certain difficulties, of course, arise in this connection, more especially the difficulty of feeding the sick, and also of providing sufficient attendants. In a civilised country one can hardly believe that the enemy would interfere with these field hospitals, and there is really nothing in the conduct of the Boers in the present campaign to lead one to suppose that they would do otherwise than treat such field hospitals if found with consideration. It is true they might take the wounded prisoners afterwards, but that is a minor matter and it seems to me that it would be worth while to attempt to come to some agreement among the nations by which field hospitals might be left on the field of battle, and furnished with suitable supplies and medical comforts. Of course, in connection with that another difficulty which would arise in the present state of our Army Medical Department, namely, its undermanned condition, would render such an idea impossible. To drop field hospitals all over the country with suitable attendants would very soon deplete the service, and leave no one at hand to go forward with the army. Something of the kind, however, would be extremely important, and no one who has realised the sufferings of the patients in this zampaign from the early transport, and the loss of life and limbs which have consequently ensued, will doubt as to the advisability of some plan of this kind. It is to be hoped that the efforts which are being made to improve the conditions of the service will attract a sufficient number of suitable men to allow a reserve supply for purposes of this kind to be available.

If once these requirements were attended to, notably better arrangements to prevent sepsis in the first instance, proper supplies of lotions and boiled water, proper illumination, diminished necessity for transporting the wounded to a dis tance, and increase in the personnel we could then look forward to a more efficient attempt being made to carry the advances of modern surgery into military practice. More especially more efficient efforts could be made to disinfect and treat bad compound fractures, to see that all cases of wounds of the skull were trephined as early as possible, to open the abdomen in cases where the wound was over a fixed portion of the intestine and where, therefore, injury of the tissues was probable, and so on.

There are a number of minor points in the treatment of wounds in the field and in the furnishing of field hospitals which I need not go into. I think that all these questions of wound treatment should be considered by a properly constituted expert committee. In the meantime, I have said enough to show that in this matter far from having reached finality in the treatment of wounds in war we have hardly begun to bring modern surgery to bear on the subject. The details in this respect are as important as the larger schemes which are occupying so much attention at the present time, and without attention to them these schemes would fail to effect the ultimate object for which they are proposed, namely, the diminution of suffering and the saving of life in war.

\section{MEDICATED LOZENGES.}

By Sir JAMES SAWYER, M.D.Lond., F.R.C.P., Senior Consulting Physician to the Queen's Hospital, Birmingham.

"Qur miscuit utile dulci" may, with apologies to Horace, be spoken of a physician who prescribes a well-medicated lozenge, who knows how to combine efficient remedies in the acceptable vehicle of a delectable sweetmeat. In many affections of the mouth and fauces, as well as in some other morbid conditions, the form of lozenge offers a convenient, agreeable, and efficacious method of administering many remedies. We owe the modern therapeutic use of lozenges in some part to the old Edinburgh Pharmacopoeia. In Dr. Paris's time, in the Twenties of the last century, he pointed out that inasmuch as trochisci, troches, or lozenges were then regarded as objects rather of confectionery than of pharmacy, neither the London nor the Dublin College condescended to notice them, while the Edinburgh Pharmacopaia contained several formulæ for their preparation, while they were undoubtedly useful in medical practice, either in the officinal forms or in certain magistral combinations, for which last Dr. Paris gave some valuable suggestions in his classical Pharmacologia. Since that time many considerations, physiological and pathological, and the use of improved diagnostic appliances, the laryngoscope to wit, have extended the use of medicated lozenges. The last edition of the British Pharmacopaia gives the formulæ for seventeen forms of trochiscus, these being made up with a "fruit basis," with a " simple basis," with a " rose basis," or with a "tolu basis." Besides these officinal lozenges there are many other medicated ones "in the market," some of them being tarred with the black mark of proprietary possession, and not a few of them being of unknown composition. In my present communication I have two objectives, namely, to encourage my brethren to prescribe lozenges in their own magistral formulæ whenever they can, and to draw professional attention to a "basis" which I have found in my own practice to be useful for the purpose. This " basis" is known as the pasta glycyrrhizæ alba, or pâte de réglisse blanche. It is described in Beasley's Pocket Formulary. It is prepared like the better known pasta althææ or pâte de Guimauve of the French Pharmacopaia, liquorice root being used instead of marsh-mallow root. This white liquorice paste is prepared from the following formula, according to Beasley : Take of decorticated liquorice root $\xi$ iv, water Oiv; macerate for 12 hours; strain and add lb.ijss of picked gum arabic and lb.ijss of refined sugar; dissolve, strain, and evaporate to the thickness of honey, constantly stirring, and add gradually the whites of 12 eggs well beaten with 3 iv of orange water; evaporate with constant stirring till the paste is so firm as not to adhere to the hands.

If the physician decide upon the exhibition in a given case of illness of a remedy in the vehicular form of a lozenge, the particular drug or drugs therapeutically indicated for this purpose in the particular case should be selected with a prescriber's usual care, and prescribed with the pasta glycyrrhizæ alba. The active drug or drugs should be skilfully combined by the dispenser, secundum artem, with the basis I have described, in the process of the making of that basis at a time before the paste attains its final consistency. For example, borax is an excellent local subastringent, detergent, and antiseptic. A lozenge of it may be prescribed magisterially as follows: B Boracis gr.ij, pastæ glycyrrhizæ albæ (Beasley) gr.x ; misce, fiat trochiscus. Signetur: one or two to be slowly sucked, as directed. A lozenge of borax so made is " nice" enough to be agreeable without being quite a sweetmeat. When freshly made it dissolves slowly and well in the mouth, and it is tough enough to be in part a masticatory. 